\title{
Association of cystathionine beta-synthase polymorphisms and aneurysmal subarachnoid hemorrhage
}

\author{
Philipp Hendrix, MD, ${ }^{1}$ Paul M. Foreman, MD, ${ }^{2}$ Mark R. Harrigan, MD, ${ }^{2}$ Winfield S. Fisher III, MD, ${ }^{2}$ \\ Nilesh A. Vyas, MD, ${ }^{3}$ Robert H. Lipsky, PhD, ${ }^{3,4}$ Mingkuan Lin, PhD, ${ }^{4}$ \\ Beverly C. Walters, MD, MSc, FRCSC, ${ }^{2-4}$ R. Shane Tubbs, PhD, ${ }^{5}$ Mohammadali M. Shoja, MD, ${ }^{6}$ \\ Jean-Francois Pittet, MD, ${ }^{7}$ Mali Mathru, MD, ${ }^{7}$ and Christoph J. Griessenauer, MD ${ }^{8,9}$
}

\begin{abstract}
1Department of Neurosurgery, Saarland University Medical Center and Saarland University Faculty of Medicine, Homburg/Saar, Germany; ${ }^{2}$ Department of Neurosurgery, University of Alabama at Birmingham, Alabama; ${ }^{3}$ Department of Neurosciences, Inova Health System, Falls Church; ${ }^{4}$ Department of Molecular Neuroscience, George Mason University, Fairfax, Virginia; ${ }^{5}$ Seattle Science Foundation, Seattle, Washington; ${ }^{6}$ Neuroscience Research Center, Tabriz University of Medical Sciences, Tabriz, Iran; ${ }^{7}$ Department of Anesthesiology, University of Alabama at Birmingham, Alabama; ${ }^{8}$ Neurosurgical Service, Beth Israel Deaconess Medical Center, Harvard Medical School, Boston, Massachusetts; and 'Department of Neurosurgery, Geisinger Health System, Danville, Pennsylvania
\end{abstract}

OBJECTIVE Cystathionine $\beta$-synthase (CBS) is involved in homocysteine and hydrogen sulfide $\left(\mathrm{H}_{2} \mathrm{~S}\right)$ metabolism. Both products have been implicated in the pathophysiology of cerebrovascular diseases. The impact of CBS polymorphisms on aneurysmal subarachnoid hemorrhage (aSAH) and its clinical sequelae is poorly understood.

METHODS Blood samples from all patients enrolled in the CARAS (Cerebral Aneurysm Renin Angiotensin System) study were used for genetic evaluation. The CARAS study prospectively enrolled aSAH patients at 2 academic institutions in the United States from 2012 to 2015 . Common CBS polymorphisms were detected using 5'exonuclease genotyping assays. Analysis of associations between CBS polymorphisms and aSAH was performed.

RESULTS Samples from 149 aSAH patients and 50 controls were available for analysis. In multivariate logistic regression analysis, the insertion allele of the 844ins68 CBS insertion polymorphism showed a dominant effect on aSAH. The GG genotype of the CBS G/A single nucleotide polymorphism (rs234706) was independently associated with unfavorable functional outcome (modified Rankin Scale Score 3-6) at discharge and last follow-up, but not clinical vasospasm or delayed cerebral ischemia (DCI).

CONCLUSIONS The insertion allele of the 844ins68 CBS insertion polymorphism was independently associated with aSAH while the GG genotype of rs234706 was associated with an unfavorable outcome both at discharge and last follow-up. Increased CBS activity may exert its neuroprotective effects through alteration of $\mathrm{H}_{2} \mathrm{~S}$ levels, and independent of clinical vasospasm and $\mathrm{DCl}$.

https://thejns.org/doi/abs/10.3171/2017.2.JNS162933

KEY WORDS cystathionine beta-synthase; polymorphism; aneurysm; subarachnoid hemorrhage; outcome; vascular disorders

YSTATHIONINE $\beta$-synthase (CBS) is an enzyme of the transsulfuration pathway and is involved in homocysteine metabolism and hydrogen sulfide $\left(\mathrm{H}_{2} \mathrm{~S}\right)$ formation. ${ }^{22,33}$ Hyperhomocysteinemia has been associated with vascular disease, ${ }^{6}$ atherosclerosis, neointima formation, ${ }^{20,29}$ vascular inflammation, endothelial dysfunction,,$^{2,10,19}$ and stroke.,11 Hydrogen sulfide has both vasodilating and vasoconstricting effects on the cardiovascular system and contributes to blood pressure regulation. ${ }^{5}$ In the nervous system, $\mathrm{CBS}$ is the key enzyme for $\mathrm{H}_{2} \mathrm{~S}$ syn-

ABBREVIATIONS ADC = apparent diffusion coefficient; aSAH = aneurysmal subarachnoid hemorrhage; CARAS = Cerebral Aneurysm Renin Angiotensin System; CBS = cystathionine $\beta$-synthase; $\mathrm{DCl}=$ delayed cerebral ischemia; $\mathrm{mRS}=$ modified Rankin Scale; $\mathrm{SNP}=$ single nucleotide polymorphism.

SUBMITTED November 24, 2016. ACCEPTED February 9, 2017.

INCLUDE WHEN CITING Published online August 4, 2017; DOI: 10.3171/2017.2.JNS162933. 
thesis ${ }^{1}$ and plays a role in angiogenesis ${ }^{30}$ and functions as a neuromodulator. ${ }^{1}$ Following aSAH, $\mathrm{H}_{2} \mathrm{~S}$ appears protective against secondary brain injury. ${ }^{8,26}$ Additionally, there is evidence that $\mathrm{H}_{2} \mathrm{~S}$ is involved in collagen metabolism and regulation of the vascular wall. ${ }^{15,27}$ Hydrogen sulfide treatment induces angiogenesis after cerebral ischemia and may be of value in regenerative recovery after stroke. ${ }^{21}$

Genetic polymorphisms of the genes encoding CBS may be associated with variable enzyme activity resulting in altered homocysteine and $\mathrm{H}_{2} \mathrm{~S}$ levels and may play a role in the pathogenesis of cerebrovascular disease. ${ }^{18,32}$ We report a prospective study of patients with aneurysmal subarachnoid hemorrhage (aSAH) to investigate the role of CBS polymorphisms in aSAH.

\section{Methods}

Blood samples from all aSAH patients and controls enrolled in the CARAS (Cerebral Aneurysm Renin Angiotensin System) study were used for genetic evaluation as previously decribed. ${ }^{12-14,17}$ The CARAS study prospectively enrolled aSAH patients at 2 academic institutions in the US from 2012 to 2015. Aneurysmal subarachnoid hemorrhage patients were treated in accordance with guidelines for the management of aSAH. The control group was composed of trauma patients, age $\geq 19$ years, with unremarkable CT angiograms of the head and neck (no cerebral aneurysm or other vascular malformation) and without known genetic risk factors for cerebral aneurysm formation. Both aSAH patients and controls were enrolled within 72 hours of admission. Institutional review board approval was obtained at both institutions and written informed consent was obtained from individual participants or their proxy.

\section{Definition of Clinical Vasospasm and Delayed Cerebral Ischemia}

Clinical vasospasm was defined as a new focal or global neurological deficit, or deterioration of at least 2 points on the Glasgow Coma Scale, not explained by another clinical process including hydrocephalus, aneurysm rebleeding, electrolyte disturbance, seizure, infection, fever, metabolic disturbance, cerebral edema, or surgical complication. CT angiography, digital subtraction angiography, and transcranial Doppler ultrasound examinations were obtained at the discretion of the treating neurosurgeon. The diagnosis of clinical vasospasm was adjudicated by consensus of the study team and treated with hyperdynamic therapy as first line. ${ }^{9}$ Hyperdynamic therapy included avoidance of hypovolemia with a goal systolic blood pressure greater than $160 \mathrm{~mm} \mathrm{Hg}$, accomplished with either permissive hypertension or vasopressor therapy. Patients with clinical vasospasm refractory to medical treatment were treated in the endovascular suite at the discretion of the treating neurosurgeon. CT scans or MRI were routinely performed when the patient was transferred from the intensive care unit to the ward with the purpose of imaging patients who receive permanent CSF diversion prior to transfer, to rule out occult hydrocephalus, and look for clinically silent cerebral infarction. Delayed cerebral ischemia (DCI) was defined as low-density areas on CT or an MRI study demonstrating a hyperintense area on a diffusion weighted imaging
TABLE 1. Common CBS polymorphisms

\begin{tabular}{lll}
\hline \multicolumn{1}{c}{ CBS Polymorphism } & Alleles & Frequency \\
\hline 844ins68 & W/I & $11.7 \%^{*}$ \\
\hline rs234706 $(699 \mathrm{G}>\mathrm{A})(\mathrm{c} .699 \mathrm{C}>\mathrm{T})$ & $\mathrm{G} / \mathrm{A}$ & $\mathrm{MAF} 0.2(\mathrm{~A}) \dagger$ \\
\hline rs1801181 $(1080 \mathrm{C}>\mathrm{T})$ & $\mathrm{C} / \mathrm{T}$ & $\mathrm{MAF} 0.3(\mathrm{~T}) \dagger$ \\
\hline I = insertion; $\mathrm{MAF}=$ minor allele frequency; $W=$ wild type. & \\
* Heterozygote insertion frequency from Tsai et al. ${ }^{35}$ & \\
† From http://useast.ensembl.org/Homo_sapiens/Info/Index.
\end{tabular}

sequence with a corresponding hypointense apparent diffusion coefficient (ADC) sequence that corresponded with a vascular territory. Infarctions or contusion seen on postoperative Day 1 imaging were considered procedurally related and were not considered DCI.

\section{Functional Outcome Assessment}

Functional outcome was recorded at the time of discharge from the acute hospital setting, and at last followup using the modified Rankin Scale (mRS). Unfavorable outcome was defined as mRS Score 3-6. All outcome data were obtained blinded to the results of the genetic analysis. Functional outcome was assessed either in clinic or via telephone interview with the patient or with a surrogate if the patient was unable to participate. ${ }^{4}$

\section{Laboratory and Genetic Evaluation}

Common $C B S$ polymorphisms (Table 1) were detected using 5'exonuclease (Taqman) genotyping assays [844ins68 CBS insertion polymorphism W>I, CBS 699 $\mathrm{G}>\mathrm{A}$ (c.699 C>T) single nucleotide polymorphism (SNP) (rs234706), and CBS $1080 \mathrm{C}>\mathrm{T}$ SNP (rs1801181)]. Commercial Taqman assays were designed and performed according to the vendor (Thermo Fisher Scientific Inc.). Approximately $10 \%$ of the DNA samples were randomly selected to test reproducibility of Taqman assays. All of the replication samples produced concordant genotypes.

\section{Statistical Analysis}

Continuous variables are presented as mean \pm standard deviation, and categorical variables are presented as frequency and percentage. Analyses were carried out using the unpaired Wilcoxon rank-sum test, Student t-test, chi-square test, and Fisher exact test, as appropriate. Patient characteristics and $C B S$ polymorphisms were tested in univariable analysis to determine predictors of aSAH. Patient and aneurysm characteristics and CBS polymorphisms were tested in univariable analysis to determine predictors of the following dependent variables: clinical vasospasm, DCI, unfavorable functional outcome at discharge (mRS Score 3-6) and upon follow-up. Factors predictive in univariable analysis $(\mathrm{p}<0.15)$ were entered into a multivariable logistic regression analysis. A p value $\leq$ 0.05 was considered statistically significant.

\section{Results}

\section{Patient and Control Characteristics}

Blood samples from 149 aSAH patients and 50 controls were analyzed. The mean ages of aSAH patients and controls were $54.9 \pm 12.5$ and $50.6 \pm 18.6$ years, respectively 
TABLE 2. Characteristics of aSAH patients and controls

\begin{tabular}{|c|c|c|c|}
\hline Characteristic & $\begin{array}{c}\text { aSAH } \\
(n=149)\end{array}$ & $\begin{array}{l}\text { Controls } \\
(n=50)\end{array}$ & $\begin{array}{c}\mathrm{p} \\
\text { Value }\end{array}$ \\
\hline Age in years, mean & $54.9 \pm 12.5$ & $50.6 \pm 18.6$ & 0.07 \\
\hline \multicolumn{4}{|l|}{ Race } \\
\hline Caucasian & $85(57.0 \%)$ & $41(82 \%)$ & 0.003 \\
\hline African American & $60(40.3 \%)$ & $7(14 \%)$ & \\
\hline Other & $4(2.7 \%)$ & $2(4 \%)$ & \\
\hline \multicolumn{4}{|l|}{ Sex } \\
\hline Male & $35(23.5 \%)$ & $18(36 \%)$ & 0.086 \\
\hline Female & $114(76.5 \%)$ & $32(64 \%)$ & \\
\hline Ischemic vascular disease & $13(8.6 \%)$ & $8(16 \%)$ & 0.153 \\
\hline Hypertension & $90(60.4 \%)$ & $20(40 \%)$ & 0.013 \\
\hline \multicolumn{4}{|l|}{ Antithrombotics } \\
\hline None & $132(88.6 \%)$ & $39(78.0 \%)$ & 0.044 \\
\hline Antiplatelets & $14(9.4 \%)$ & $11(22.0 \%)$ & \\
\hline Anticoagulation & $3(2.0 \%)$ & 0 & \\
\hline \multicolumn{4}{|l|}{ Smoking } \\
\hline Never & $58(38.9 \%)$ & $21(42 \%)$ & 0.426 \\
\hline Former & $18(12.1 \%)$ & $9(18 \%)$ & \\
\hline Current & $73(49 \%)$ & $20(40 \%)$ & \\
\hline Family history & $14(9.4 \%)$ & $0(0 \%)$ & 0.025 \\
\hline $\begin{array}{l}\text { Symptom onset to admission in } \\
\text { days, mean }\end{array}$ & $0.9 \pm 2.7$ & & \\
\hline \multicolumn{4}{|l|}{ Aneurysm size } \\
\hline$<7 \mathrm{~mm}$ & $93(62.4 \%)$ & & \\
\hline $7-12 \mathrm{~mm}$ & $49(32.9 \%)$ & & \\
\hline $13-24 \mathrm{~mm}$ & $6(4.0 \%)$ & & \\
\hline$\geq 25 \mathrm{~mm}$ & $1(0.7 \%)$ & & \\
\hline \multicolumn{4}{|l|}{ Location } \\
\hline Anterior & $120(80.5 \%)$ & & \\
\hline Posterior & $29(19.5 \%)$ & & \\
\hline \multicolumn{4}{|l|}{ Hunt \& Hess grade } \\
\hline $1-3$ & $115(77.2 \%)$ & & \\
\hline $4-5$ & $34(22.8 \%)$ & & \\
\hline \multicolumn{4}{|l|}{ Fisher CT grade } \\
\hline $1-2$ & $23(15.4 \%)$ & & \\
\hline $3-4$ & $126(84.6 \%)$ & & \\
\hline \multicolumn{4}{|l|}{ Modified Fisher CT grade* } \\
\hline $1-2$ & $59(49.2 \%)$ & & \\
\hline $3-4$ & $61(50.8 \%)$ & & \\
\hline \multicolumn{4}{|l|}{ Hijdra scale* } \\
\hline 0 & $29(24.2 \%)$ & & \\
\hline 1 & $10(8.3 \%)$ & & \\
\hline 2 & $24(20.0 \%)$ & & \\
\hline 3 & $20(16.7 \%)$ & & \\
\hline 4 & $7(5.8 \%)$ & & \\
\hline 5 & $4(3.3 \%)$ & & \\
\hline 6 & $11(9.2 \%)$ & & \\
\hline 7 & $5(4.2 \%)$ & & \\
\hline 8 & $4(3.3 \%)$ & & \\
\hline 9 & 0 & & \\
\hline 10 & $5(4.2 \%)$ & & \\
\hline 11 & $1(0.8 \%)$ & & \\
\hline \multicolumn{4}{|l|}{ Treatment† } \\
\hline Microsurgical clipping & $76(52.4 \%)$ & & \\
\hline Endovascular treatment & $69(47.6 \%)$ & & \\
\hline
\end{tabular}

CONTINUED IN NEXT COLUMN »
» CONTINUED FROM PREVIOUS COLUMN

TABLE 2. Characteristics of aSAH patients and controls

\begin{tabular}{|c|c|c|c|}
\hline Characteristic & $\begin{array}{c}\text { aSAH } \\
(n=149)\end{array}$ & $\begin{array}{l}\text { Controls } \\
(n=50)\end{array}$ & $\begin{array}{c}p \\
\text { Value }\end{array}$ \\
\hline Rerupture & $7(4.7 \%)$ & & \\
\hline Clinical vasospasm & $34(22.8 \%)$ & & \\
\hline $\mathrm{DCl}$ & $31(21.2 \%)$ & & \\
\hline Hyponatremia & $56(37.6 \%)$ & & \\
\hline $\begin{array}{l}\text { Infection (bloodstream, pneumo- } \\
\text { nia, urinary tract) }\end{array}$ & $61(40.9 \%)$ & & \\
\hline Ventriculitis & $4(2.7 \%)$ & & \\
\hline AED administration & $62(41.6 \%)$ & & \\
\hline ICU stay in days, mean & $11.9 \pm 7.9$ & & \\
\hline Hospital stay in days, mean & $15.9 \pm 11.3$ & & \\
\hline $\begin{array}{l}\text { Discharge mRS score } \\
\text { 0-2 } \\
3-6\end{array}$ & $\begin{array}{l}71(47.7 \%) \\
78(52.3 \%)\end{array}$ & & \\
\hline $\begin{array}{l}\text { mRS score at last follow-up } \\
0-2 \\
3-6\end{array}$ & $\begin{array}{l}92(61.7 \%) \\
57(38.3 \%)\end{array}$ & & \\
\hline Length of follow-up in days, mean & $249.7 \pm 187.8$ & & \\
\hline \multicolumn{4}{|c|}{$\begin{array}{l}\text { AED }=\text { antiepileptic drug. } \\
\text { Values represent the number of patients unless otherwise indicated. Means } \\
\text { are presented } \pm \text { SD. } \\
\text { * Data were not available for } 29 \text { patients. } \\
\text { † Data were not available for } 4 \text { aneurysms. } \\
\ddagger \text { Data were not available for } 3 \text { patients. }\end{array}$} \\
\hline
\end{tabular}

$(p=0.07)$. Sex was evenly distributed between the two groups $(\mathrm{p}=0.086)$. There was no difference in the rate of current or former smokers $(p=0.426)$. The majority of ruptured aneurysms were less than $7 \mathrm{~mm}$ in maximum diameter $(62.4 \%)$ and located in the anterior circulation (80.5\%). The Hunt and Hess grade was I-III in $77.2 \%$ of cases and the modified Fisher CT grade was 1-2 in $49.2 \%$. Clinical vasospasm and DCI occurred in $22.8 \%$ and $21.2 \%$, respectively. Favorable functional outcome (mRS Score 0-2) at hospital discharge and last follow-up was achieved in $47.7 \%$ and $61.7 \%$ of patients, respectively (Table 2).

\section{Association of CBS Polymorphisms and aSAH}

All $C B S$ polymorphisms were in Hardy-Weinberg equilibrium in patients and controls with the exception of rs1801181 in aSAH patients $(\mathrm{p}=0.009)$ (Table 3). In multivariate logistic regression analysis, the insertion allele of the 844ins68 CBS insertion polymorphism showed a dominant effect on aSAH (OR 3.046, 95\% CI 1.049-8.846, p $=0.041)$ in a model that included age, race, and antithrombotic use (Table 4 ).

\section{Association of CBS Polymorphisms and Clinical Course After aSAH}

In multivariate logistic regression analysis, the GG genotype of rs234706 was associated with an unfavorable outcome at discharge (OR 5.295, 95\% CI 1.571-17.840, p $=0.007)$. Other predictors of an unfavorable functional 
TABLE 3. Genotype frequencies of CBS polymorphisms

\begin{tabular}{|c|c|c|c|}
\hline Polymorphism \& Genotype & aSAH Pts & Controls & $p$ Value \\
\hline \multicolumn{4}{|l|}{ 844ins68* } \\
\hline WW & 95 & 44 & \multirow{3}{*}{0.004} \\
\hline $\mathrm{WI}$ & 43 & 5 & \\
\hline II & 7 & 0 & \\
\hline HWE & $p=0.462$ & $p=0.707$ & \\
\hline \multicolumn{4}{|l|}{ rs234706† } \\
\hline GG & 74 & 24 & \multirow{3}{*}{0.926} \\
\hline$A G$ & 59 & 21 & \\
\hline AA & 14 & 4 & \\
\hline HWE & $p=0.655$ & $p=0.842$ & \\
\hline \multicolumn{4}{|l|}{ rs1801181† } \\
\hline $\mathrm{CC}$ & 73 & 20 & \multirow{3}{*}{0.562} \\
\hline CT & 51 & 20 & \\
\hline TT & 23 & 9 & \\
\hline HWE & $p=0.009$ & $p=0.326$ & \\
\hline
\end{tabular}

HWE = Hardy-Weinberg equilibrium; pts = patients.

* Alleles were not available for 4 aSAH patients and 1 control.

$\dagger$ Alleles were not available for 2 aSAH patients and 1 control.

outcome at discharge were days for symptom onset to admission (OR 1.377, 95\% CI 1.025-1.851, $\mathrm{p}=0.034$ ), higher Hunt and Hess grade (OR 2.798, 95\% CI 1.397-5.604, $\mathrm{p}=$ 0.004), higher modified Fisher CT grade (OR 2.304, 95\% CI $1.293-4.107, \mathrm{p}=0.005$ ), and antiepileptic drug administration (OR 4.419, 95\% CI 1.329-14.697, $\mathrm{p}=0.015$ ). Hyponatremia was protective in the model (OR $0.202,95 \%$ CI 0.062-0.658, $\mathrm{p}=0.008$ ) (Table 5).

The GG genotype of rs234706 was also associated with an unfavorable outcome at last follow-up (OR 3.008, 95\% CI 1.243-7.276, $\mathrm{p}=0.015)$. Delayed cerebral ischemia (OR 4.436, 95\% CI 1.608-12.238, $\mathrm{p}=0.004)$, higher Hunt and Hess grade (OR 2.772, 95\% CI 1.732-4.436, p $<0.001$ ), and posterior circulation aneurysms (OR 4.619, 95\% CI 1.631-13.078, $\mathrm{p}=0.004)$ were other predictors of an unfavorable outcome at last follow-up (Table 5).

None of the $C B S$ polymorphisms were associated with clinical vasospasm, DCI, or aneurysm rebleeding.

\section{Discussion}

Cystathionine $\beta$-synthase polymorphisms appear to play a role in the pathophysiology of aSAH and its clinical sequelae. The insertion allele of the 844ins68 CBS insertion polymorphism was associated with aSAH, while the GG genotype of rs234706 was associated with an unfavorable outcome both at discharge and last follow-up.

\section{Cystathionine $\beta$-Synthase and aSAH}

The insertion allele of the 844ins68 CBS insertion polymorphism was found to be significantly associated with aSAH. In North America, $11.7 \%$ of the population is heterozygous for 844ins $68 .{ }^{35}$ The frequency of the insertion allele of 844ins68 ranges between 5\% and $40 \%$ among different ethnicities worldwide. ${ }^{31}$ While the insertion allele of 844ins68 has been linked to a gain-of-function of the CBS enzyme, ${ }^{18}$ others have reported that this polymorphism
TABLE 4. Predictors of aSAH in multivariable logistic regression analysis

\begin{tabular}{lcc}
\hline \multicolumn{1}{c}{ Variable } & OR $(95 \% \mathrm{Cl})$ & $\mathrm{p} \mathrm{Value}$ \\
\hline Older age & $1.036(1.010-1.063)$ & 0.007 \\
\hline African American & $2.764(1.072-7.128)$ & 0.035 \\
\hline Antithrombotics & $0.357(0.133-0.961)$ & 0.041 \\
\hline WI \& II vs WW genotype (844ins68) & $3.046(1.049-8.846)$ & 0.041 \\
\hline
\end{tabular}

had no effect on plasma homocysteine levels. ${ }^{23,34,35}$ Cystathionine $\beta$-synthase also catalyzes the formation of $\mathrm{H}_{2} \mathrm{~S}$. Endogenous $\mathrm{H}_{2} \mathrm{~S}$, as well as carbon monoxide (CO) and nitric oxide (NO), play a role in pulmonary artery collagen remodeling in rats with high pulmonary blood flow. 16,27,36 Hydrogen sulfide also has a regulatory effect on vascular collagen content in hypertensive rats. ${ }^{38}$ Polymorphisms of $C B S$ may be associated with altered $\mathrm{H}_{2} \mathrm{~S}$ levels that subsequently impact collagen metabolism in cerebral vessels. This alteration in the composition of the blood vessel may contribute to aneurysm formation and aSAH.

\section{CBS and Clinical Course After Subarachnoid Hemorrhage}

Grobelny el at. found the insertion allele of the 844ins68 $C B S$ polymorphism to be protective against DCI following aSAH, while the TT genotype of rs1801181 was associated with an increased risk of DCI.$^{18}$ Collectively, they hypothesized that gain-of-function $C B S$ polymorphisms increased $\mathrm{H}_{2} \mathrm{~S}$, which subsequently protects against DCI. However, they also observed a trend for an increased risk for angiographic cerebral vasospasm associated with $C B S$ gain-of-function polymorphisms. Hence, they concluded that the protective effect against DCI is independent of the protective effect against large-vessel cerebral vasospasm. ${ }^{18}$ In the present study, the GG genotype of rs234706 was associated with an unfavorable outcome both at discharge and at last follow-up. This accounts not only for an increased risk for DCI but also for an increased risk of an unfavorable outcome at discharge and follow-up (Fig. 1). Grobelny et al ${ }^{18}$ hypothesized that the protective mechanism of gain-of-function polymorphisms lies in the production of $\mathrm{H}_{2} \mathrm{~S}$. Recent findings by Cui et al. ${ }^{8}$ support this hypothesis. In a mouse model, aSAH caused decreased $\mathrm{H}_{2} \mathrm{~S}$ and CBS levels that were restored following administration of exogenous $\mathrm{NaHS}$, which serves as an $\mathrm{H}_{2} \mathrm{~S}$ donor. NaHS administration increased blood-brain barrier integrity, restored plasma inflammatory cytokine levels, and attenuated apoptosis and cerebral vasospasm. ${ }^{8} \mathrm{Li}$ et al. ${ }^{26}$ also reported neuroprotective effects of $\mathrm{H}_{2} \mathrm{~S}$ administration in a rat aSAH model. Administration of NaHS after SAH decreased mortality, attenuated brain edema, decreased neuronal cell death, reduced neurological deficits, and improved neurobehavioral outcome. ${ }^{26}$ Despite promising findings in aSAH, $\mathrm{H}_{2} \mathrm{~S}$ was found to actually have deleterious effects in acute ischemic stroke. In a study by Wong et al. ${ }^{37}$ involving a rat stroke model, endogenous $\mathrm{H}_{2} \mathrm{~S}$ was elevated following stroke and cysteine administration increased infarct volume, potentially by increasing $\mathrm{H}_{2} \mathrm{~S}$. This effect was abolished by application of a CBS inhibitor. ${ }^{37}$ Exogenous administration of NaHS significantly increased cerebral ischemic damage. ${ }^{32}$ Chemically, $\mathrm{H}_{2} \mathrm{~S}$ is a 
TABLE 5. Predictors of outcome measures in aSAH in multivariable logistic regression analysis

\begin{tabular}{lll}
\hline \multicolumn{1}{c}{ Outcome \& Variable } & OR $(95 \% \mathrm{Cl})$ & $\mathrm{p} \mathrm{Value}$ \\
\hline Unfavorable outcome at discharge (mRS Score 3-6) & & 0.034 \\
\hline Days for symptom onset to admission & $1.377(1.025-1.851)$ & 0.004 \\
\hline Higher Hunt \& Hess grade & $2.798(1.397-5.604)$ & 0.005 \\
\hline Higher modified Fisher CT grade & $2.304(1.293-4.107)$ & 0.016 \\
\hline Higher Hijdra grade & $1.405(1.067-1.850)$ & 0.008 \\
\hline Hyponatremia & $0.202(0.062-0.658)$ & 0.015 \\
\hline AED administration & $4.419(1.329-14.697)$ & 0.007 \\
\hline GG vs GA \& AA genotype (rs234706) & $5.295(1.571-17.840)$ & 0.004 \\
\hline Unfavorable outcome at follow-up (mRS Score 3-6) & & 0.000 \\
\hline DCl & $4.436(1.608-12.238)$ & 0.004 \\
\hline Higher Hunt \& Hess grade & $2.772(1.732-4.436)$ & 0.015 \\
\hline Posterior location & $4.619(1.631-13.078)$ & \\
\hline GG vs GA \& AA genotype (rs234706) & $3.008(1.243-7.276)$ & \\
\hline
\end{tabular}

gaseous transmitter that is difficult to measure and acts on vascular smooth-muscle cells, resulting in vasodilatation similar to $\mathrm{NO}$ and $\mathrm{CO} .{ }^{25}$ Hydrogen sulfide has been shown to have both vasodilating and vasoconstricting effects depending on type of vessel, endothelial function, and $\mathrm{H}_{2} \mathrm{~S}$ concentration. $5,24,28$ The interplay of gaseous transmitters and their functions remains poorly understood. Thus, we cannot draw final conclusions on how $\mathrm{H}_{2} \mathrm{~S}$ alters the clinical course of patients who suffered from aSAH. However, common CBS polymorphisms may result in alterations of homocysteine and particularly hydrogen sulfide $\left(\mathrm{H}_{2} \mathrm{~S}\right)$ levels that affect the clinical course.

\section{Limitations}

This study's small sample size is a limitation as larger samples are preferred for association studies. As such, findings should be interpreted with caution until larger data sets are available for analysis. Race distribution was

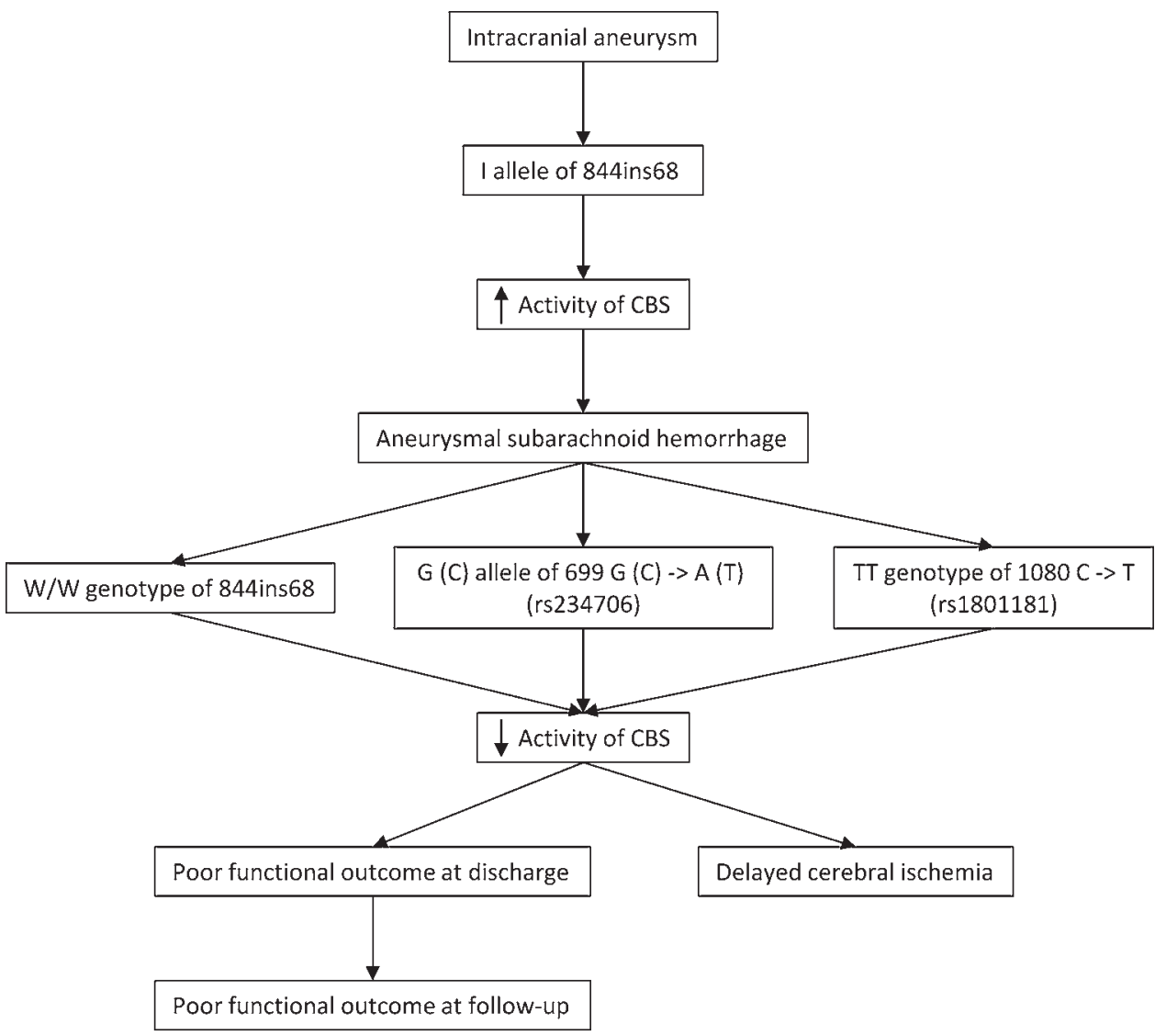

FIG. 1. Proposed mechanism of CBS activity in aSAH. 
not well matched between aSAH patients and controls. The association of the insertion allele of the 844ins68 CBS insertion polymorphism with aSAH, however, remained significant in a multivariable regression model that included race. The study did not assess whether common $C B S$ polymorphisms altered transcription or the biological character of the proteins encoded. Neither substrates nor products of the herein assessed CBS polymorphisms such as homocysteine or $\mathrm{H}_{2} \mathrm{~S}$ were measured. One SNP was not in Hardy-Weinberg equilibrium. This may be a result of genetic drift or variation in the relative frequency of different genotypes in a small population due to the chance that particular genes disappear as individuals die or do not reproduce. Certain genotypes may also represent a survival disadvantage following aSAH or result in a decreased risk for cerebral aneurysm formation or rupture.

\section{Conclusions}

The insertion allele of the 844ins68 CBS insertion polymorphism was independently associated with aSAH. This gain-of-function polymorphism is hypothesized to influence collagen metabolism, predisposing to aneurysm formation and rupture. The GG genotype of rs234706 was associated with an unfavorable outcome both at discharge and last follow-up, potentially reflecting a role of $\mathrm{H}_{2} \mathrm{~S}$ in neuroprotection following aSAH.

\section{Acknowledgments}

We would like to thank the participants in this study and the efforts of the neurosurgical research coordinators at Inova Health System for their work and contribution to the CARAS Study. We would also like to thank the Department of Anesthesiology at the University of Alabama at Birmingham, the Brain Aneurysm Foundation, and the family of Timothy P. Susco for their generous support of the present study.

\section{References}

1. Abe K, Kimura H: The possible role of hydrogen sulfide as an endogenous neuromodulator. J Neurosci 16:1066-1071, 1996

2. Austin RC, Lentz SR, Werstuck GH: Role of hyperhomocysteinemia in endothelial dysfunction and atherothrombotic disease. Cell Death Differ 11 (Suppl 1):S56-S64, 2004

3. Boysen G, Brander T, Christensen H, Gideon R, Truelsen T: Homocysteine and risk of recurrent stroke. Stroke 34:12581261,2003

4. Bruno A, Akinwuntan AE, Lin C, Close B, Davis K, Baute V, et al: Simplified Modified Rankin Scale Questionnaire: reproducibility over the telephone and validation with quality of life. Stroke 42:2276-2279, 2011

5. Cacanyiova S, Berenyiova A, Kristek F: The role of hydrogen sulphide in blood pressure regulation. Physiol Res 65 (Supplementum 3):S273-S289, 2016

6. Clarke R, Daly L, Robinson K, Naughten E, Cahalane S, Fowler B, et al: Hyperhomocysteinemia: an independent risk factor for vascular disease. N Engl J Med 324:1149-1155, 1991

7. Connolly ES Jr, Rabinstein AA, Carhuapoma JR, Derdeyn CP, Dion J, Higashida RT, et al: Guidelines for the management of aneurysmal subarachnoid hemorrhage: a guideline for healthcare professionals from the American Heart Association/American Stroke Association. Stroke 43:1711-1737, 2012
8. Cui Y, Duan X, Li H, Dang B, Yin J, Wang Y, et al: Hydrogen sulfide ameliorates early brain injury following subarachnoid hemorrhage in rats. Mol Neurobiol 53:3646-3657, 2016

9. Dankbaar JW, Slooter AJ, Rinkel GJ, Schaaf IC: Effect of different components of triple-H therapy on cerebral perfusion in patients with aneurysmal subarachnoid haemorrhage: a systematic review. Crit Care 14:R23, 2010

10. De Bree A, Verschuren WMM, Kromhout D, Kluijtmans LAJ, Blom HJ: Homocysteine determinants and the evidence to what extent homocysteine determines the risk of coronary heart disease. Pharmacol Rev 54:599-618, 2002

11. Del Ser T, Barba R, Herranz AS, Seijas V, López-Manglano $\mathrm{C}$, Domingo J, et al: Hyperhomocyst(e)inemia is a risk factor of secondary vascular events in stroke patients. Cerebrovasc Dis 12:91-98, 2001

12. Foreman PM, Chua M, Harrigan MR, Fisher WS III, Tubbs RS, Shoja MM, et al: Antifibrinolytic therapy in aneurysmal subarachnoid hemorrhage increases the risk for deep venous thrombosis: a case-control study. Clin Neurol Neurosurg 139:66-69, 2015

13. Foreman PM, Chua MH, Harrigan MR, Fisher WS III, Tubbs RS, Shoja MM, et al: External validation of the Practical Risk Chart for the prediction of delayed cerebral ischemia following aneurysmal subarachnoid hemorrhage. J Neurosurg [epub ahead of print May 13, 2016. DOI: 10.3171/2016.1.JNS152554]

14. Foreman PM, Chua M, Harrigan MR, Fisher WS III, Vyas NA, Lipsky RH, et al: Association of nosocomial infections with delayed cerebral ischemia in aneurysmal subarachnoid hemorrhage. J Neurosurg 125:1383-1389, 2016

15. Gomez I, Ozen G, Deschildre C, Amgoud Y, Boubaya L, Gorenne I, et al: Reverse regulatory pathway (H2S / PGE2 / MMP) in human aortic aneurysm and saphenous vein varicosity. PLoS One 11:e0158421, 2016

16. Gong LM, Du JB, Shi L, Shi Y, Tang CS: Effects of endogenous carbon monoxide on collagen synthesis in pulmonary artery in rats under hypoxia. Life Sci 74:1225-1241, 2004

17. Griessenauer CJ, Tubbs RS, Foreman PM, Chua MH, Vyas NA, Lipsky RH, et al: Associations of renin-angiotensin system genetic polymorphisms and clinical course after aneurysmal subarachnoid hemorrhage. J Neurosurg [epub ahead of print June 10, 2016. DOI: 10.3171/2016.4.JNS16409]

18. Grobelny BT, Ducruet AF, DeRosa PA, Kotchetkov IS, Zacharia BE, Hickman ZL, et al: Gain-of-function polymorphisms of cystathionine $\beta$-synthase and delayed cerebral ischemia following aneurysmal subarachnoid hemorrhage. J Neurosurg 115:101-107, 2011

19. Harker LA, Slichter SJ, Scott CR, Ross R: Homocystinemia. Vascular injury and arterial thrombosis. N Engl J Med 291:537-543, 1974

20. Hofmann MA, Lalla E, Lu Y, Gleason MR, Wolf BM, Tanji $\mathrm{N}$, et al: Hyperhomocysteinemia enhances vascular inflammation and accelerates atherosclerosis in a murine model. $\mathbf{J}$ Clin Invest 107:675-683, 2001

21. Jang H, Oh MY, Kim YJ, Choi IY, Yang HS, Ryu WS, et al: Hydrogen sulfide treatment induces angiogenesis after cerebral ischemia. J Neurosci Res 92:1520-1528, 2014

22. Jhee KH, Kruger WD: The role of cystathionine $\beta$-synthase in homocysteine metabolism. Antioxid Redox Signal 7:813822,2005

23. Kluijtmans LA, Boers GH, Trijbels FJ, van Lith-Zanders HM, van den Heuvel LP, Blom HJ: A common 844INS68 insertion variant in the cystathionine beta-synthase gene. Biochem Mol Med 62:23-25, 1997

24. Kubo S, Doe I, Kurokawa Y, Nishikawa H, Kawabata A: Direct inhibition of endothelial nitric oxide synthase by hydrogen sulfide: contribution to dual modulation of vascular tension. Toxicology 232:138-146, 2007

25. Leffler CW, Parfenova H, Jaggar JH, Wang R: Carbon mon- 
oxide and hydrogen sulfide: gaseous messengers in cerebrovascular circulation. J Appl Physiol (1985) 100:1065-1076, 2006

26. Li T, Liu H, Xue H, Zhang J, Han X, Yan S, et al: Neuroprotective effects of hydrogen sulfide against early brain injury and secondary cognitive deficits following subarachnoid hemorrhage. Brain Pathol 27:51-63, 2017

27. Li X, Jin H, Bin G, Wang L, Tang C, Du J: Endogenous hydrogen sulfide regulates pulmonary artery collagen remodeling in rats with high pulmonary blood flow. Exp Biol Med (Maywood) 234:504-512, 2009

28. Lim JJ, Liu YH, Khin ESW, Bian JS: Vasoconstrictive effect of hydrogen sulfide involves downregulation of cAMP in vascular smooth muscle cells. Am J Physiol Cell Physiol 295:C1261-C1270, 2008

29. Morita H, Kurihara H, Yoshida S, Saito Y, Shindo T, OhHashi Y, et al: Diet-induced hyperhomocysteinemia exacerbates neointima formation in rat carotid arteries after balloon injury. Circulation 103:133-139, 2001

30. Papapetropoulos A, Pyriochou A, Altaany Z, Yang G, Marazioti A, Zhou Z, et al: Hydrogen sulfide is an endogenous stimulator of angiogenesis. Proc Natl Acad Sci U S A 106:21972-21977, 2009

31. Pepe G, Vanegas OC, Rickards O, Giusti B, Comeglio P, Brunelli T, et al: World distribution of the T833C/844INS68 CBS in cis double mutation: a reliable anthropological marker. Hum Genet 104:126-129, 1999

32. Qu K, Chen CPLH, Halliwell B, Moore PK, Wong PTH: Hydrogen sulfide is a mediator of cerebral ischemic damage. Stroke 37:889-893, 2006

33. Selhub J: Homocysteine metabolism. Annu Rev Nutr 19:217-246, 1999

34. Sperandeo MP, de Franchis R, Andria G, Sebastio G: A 68 bp insertion found in a homocystinuric patient is a common variant and is skipped by alternative splicing of the cystathionine $\beta$-synthase mRNA. Am J Hum Genet 59:1391-1393, 1996 (Letter)

35. Tsai MY, Bignell M, Schwichtenberg K, Hanson NQ: High prevalence of a mutation in the cystathionine $\beta$-synthase gene. Am J Hum Genet 59:1262-1267, 1996

36. Wei B, Du J, Cong B: Study of reversing effect of nitric oxide precursor on collagen accumulation in pulmonary artery. Chin Pharm 14:653-654, 2003

37. Wong PTH, Qu K, Chimon GN, Seah ABH, Chang HM, Wong MC, et al: High plasma cyst(e)ine level may indicate poor clinical outcome in patients with acute stroke: possible involvement of hydrogen sulfide. J Neuropathol Exp Neurol 65:109-115, 2006

38. Zhao X, Zhang LK, Zhang CY, Zeng XJ, Yan H, Jin HF, et al: Regulatory effect of hydrogen sulfide on vascular collagen content in spontaneously hypertensive rats. Hypertens Res 31:1619-1630, 2008

\section{Disclosures}

The authors report no conflict of interest concerning the materials or methods used in this study or the findings specified in this paper.

\section{Author Contributions}

Conception and design: Griessenauer, Hendrix, Foreman, Harrigan, Fisher, Tubbs, Shoja. Acquisition of data: Griessenauer, Foreman, Vyas, Lipsky, Lin. Analysis and interpretation of data: Griessenauer, Hendrix, Foreman, Lipsky, Lin. Drafting the article: Griessenauer, Hendrix. Critically revising the article: Griessenauer, Hendrix, Foreman, Fisher, Vyas, Lipsky, Lin, Walters, Tubbs, Shoja, Pittet, Mathru. Reviewed submitted version of manuscript: Griessenauer, Hendrix, Foreman, Harrigan, Vyas, Lipsky, Lin, Walters, Tubbs, Shoja, Pittet, Mathru. Approved the final version of the manuscript on behalf of all authors: Griessenauer. Statistical analysis: Hendrix, Fisher. Administrative/technical/material support: Griessenauer, Hendrix, Harrigan, Fisher, Walters, Tubbs, Shoja, Pittet, Mathru. Study supervision: Griessenauer, Harrigan, Walters, Tubbs, Shoja, Pittet, Mathru.

\section{Correspondence}

Christoph J. Griessenauer, Beth Israel Deaconess Medical Center, Harvard Medical School, 110 Francis St., Ste. 3B, Boston, MA 02215. email: christoph.griessenauer@gmail.com. 